\title{
Fazendo as palavras render: o inconsciente é infantil?
}

\author{
Sírio Possenti \\ IEL/UNICAMP
}

\section{Abstract}

Morphologically-triggered humor is seen by some studies as if it was the result of free manipulations of certain linguistic expressions. However, it is possible to show that they deal with a linguistic activity governed by a very rigorous principle, the oquivalent of a more vulgar version of de Saussure's theory of sign, the one that does not take into account his theory of value. The present work analyses $a$ set of data and seeks to demonstrate that this linguistic activity, which could "only be seen as ludic," reveals a particular way of functioning of language, based on a peculiar theory of literal meaning, in spite of contrary expectations. The central claim is that, if this peculiar theory of meaning is valid for every linguistic manifestation, language could not be considered struature (this is a good anti-structuralist argument, by the way), but "nomenclatures", that is, lists of words. The result of this work adds to all those which make up the assumption that languages are better analysed when viewed from various standpoints. 
0 objetivo primeiro deste trabalho é permitir um pouco de diversão a seu autor e aos eventuais leitores. Além disso, tem a finalidade de mostrar, através da análise de um conjunto de dados cujo efeito é tipicamente humorístico, que a duplicidade de sentidos de palavras ou de outro tipo qualquer de expressão não depende jamais de uma ação interpretativa livre do leitor, como poderia pensar um pós-estruturalista exacerbado. Ao contrário, pode-se mostrar que o duplo sentido depende sempre de um princípio, de uma regra ou de uma teoria, às vezes parecendo agir apenas localmente, mas que é sempre a mesma. o que pretendo mostrar aqui é que, de uma forma ou de outra, segue-se um princípio, uma regra ou uma teoria também nos procedimentos de descoberta que revelam sentidos inesperados no material lingüístico.

Nos dados aqui analisados, a operação de descoberta de sentidos inesperados é efetuada, de forma talvez surpreendente, a partir de uma "teoria" peculiar do sentido literal e de um método de descoberta típico da lingüística estrutural, embora aplicado com a necessária falta de rigor, tendo em vista os objetivos, isto é, os efeitos de sentido que a ocorrência desses dados procura. O sentido literal, diga-se de passagem, parece sair fortalecido no discurso do Outro. Por tabela, este trabalho acaba sendo um argumento contra uma famosa afirmação de Lacan, segundo a qual o inconsciente é estruturado como uma linguagem, o que quer que ela signifique (a não ser que "estruturado" não signifique 'estruturado') .

Considerem-se, como primeiro exemplo, os seguintes itens do dicionário ETMOLŌGICO de Millôr Fernandes:

(1) CoMICHÃo - devora terra (come chão)

Consumo - o que ainda não foi expremido (com sumo) Desenvolta - dez pessoas cercando uma (dez em volta) Destroços - uma dezena de coisas (dez trogos) FASCINANTES - certas mulheres que antes de cederem acenam que $\operatorname{sim}$ (faz sim antes) 
JANOTA - começa a perceber (já nota)

Sentimental - faltando-me tu eu fico cerebral (sem ti mental)

VERGASTAR - assistir a uma pessoa fazendo despesas (ver gastar) ${ }^{1}$

Antes de tomar conhecimento de tais definições, dificilmente ocorreria a algum falante do português interpretar dessa forma essas palavras, ao encontrá-las em textos. Provavelmente, isto seria raro mesmo quando essas palavras fossem apresentadas isoladamente, a não ser que um falante as pronunciasse de forma muito marcada, como se quisesse indicar uma possível divisão lexical. Por outro lado, elas são exemplos interessantes do que se chama de heterogeneidade do discurso (Authier-Révuz, 1982), entre numerosos outros. Em termos genéricos, pode-se dizer que é um dos casos em que, sob as palavras, encontram-se outras palavras (ver Starobinsky, 1971). Ou, dito de outro modo, outros discursos talvez o discurso do Outro. Segundo uma terminologia um pouco mais conhecida, embora não de todo equivalente, pode-se dizer simplesmente que se encontram sentidos inesperados, ou, simplesmente, outros sentidos.

Parece ser muito interessante explicitar o caminho ou as regras a partir das quais o autor deste peculiar dicionário que faz rir chega a definições como as acima. Se se tem um treinamento mínimo, não é necessário muito esforço para verificar que as "outras palavras" são descobertas pela aplicação de um procedimento análogo ao utilizado pelo estruturalismo para a descoberta das unidades linguísticas elementares: o método de comutação. Como se sabe, tal método consiste, basicamente, na localização de um elemento funcional (isto é, significativo) e na sua substituição por outro - ou por nada, caso em que se pode encontrar um exemplo de morfema zero. Se desta operação resultarem unidades gramaticais e/ou de sentido, o processo leva à descoberta de uma unidade em uma língua. Caso contrário, descobre-se que se trata de mera e coincidente identidade material, sem papel estrutural e/ou significativo - embora com produtivo papel heurístico. Por exemplo, suponha-se alguém que acaba de chegar de Marte e aprendeu uma unidade linguística do português. Digamos, a palavra "tal". Se, em seguida, ouve a seqüência "sentimental", pode ser tentado a isolar a porção "tal", e, em seguida, a verificar se a sequiência 
restante também é significativa, isto é, uma unidade linguística. Se não for (e "sentimen-" não é uma unidade, em português, nem mesmo no discurso do Outro...), então "tal" também não o é, neste lugar, embora a sequiência que pode ser reconhecida como "a mes. ma" seja uma unidade em outro paradigma, por exemplo, nas ocorrências "ele é o tal", "tal e qual", "tal pai, tal filho", etc.

1 pela aplicação intuitiva deste método aos itens definidos por Millôr que seu leitor chega à descoberta daquilo que motiva a definição fornecida pelo humorista. Ās vezes, como no caso de "desenvolta" e "fascinantes", além da aplicação do método de comutação, é necessário promover algumas alterações fonético-fonológicas no caso, pelo menos a abertura da vogal arredondada (isto é, a vogal grafada "o" de "volta") ; a substituição da consoante nasal (" $n$ ") de -scin-, e a conseqüente reestruturação silábica: o " $n$ " deixa de ser o primeiro elemento da sílaba "nan", para que se possa vislumbrar a palavra "sim" na seqüência -scin- e para que o final da cadeia coincida com a palavra "antes". Também é preciso colocar-se num dialeto específico, ou controlar o viés normativo, para admitir a concordância de "faz" com "mulheres". Mas o Outro não é muito exigente quanto a estes detalhes, o que confere facilidades metodológicas extra aos seguidores de epistemólogos como Lacan, dispensados da exigência da exatidão no teste empírico das hipóteses, facilidades negadas a quem trabalha com o aspecto público da linguagem e com alguma crença na existência de um real que não seja imaginário (Talvez isso explique o sucesso do psicanalismo, pelo menos entre os não-especialistas em psicanálise.).

Vale a pena repetir que este procedimento de segmentação alternativa é um dos mais poderosos meios de produzir humor. Ele produz a maioria dos jogos de linguagem conhecidos. Além disso, é um dos mecanismos de produção de humor mais estudados, talvez injustamente. Aqui, o interesse principal é mostrar a vigência radical de uma regra, mais do que estudar seus efeitos.

Não é necessário demonstrar neste momento que definições como as oferecidas por Millôr não resistem a um teste no nível do enunciado, a não ser talvez por acaso, como no conhecido "sentimental eu sou". Fazendo algumas manobras sintáticas que produzem estruturas pouco frequientes, pode-se descobrir que a coincidência se dá também em outros casos. Por exemplo, "Vou ver gastar (vergastar) o cara que ganhou na loto" = "Vou ver o cara 
que ganhou na loto gastar". Mas tais coincidências são proporcionalmente pouco numerosas. O usual é que não se possa ultrapassar o nível da palavra. Não se pode dizer, por exemplo, "Fulano é um janota" com o sentido de 'Fulano é um começa a perceber'. Em casos como estes, a análise do Outro só resiste com as palavras postas em estado de dicionário. ${ }^{2}$ Se resiste também num discurso, cabe ao analista demonstrar.

Em resumo, um linguiista usa critérios bastante objetivos, depois de circunscrever a língua de certo modo, e descobre quais seqüências são palavras e morfemas. Mas é possível divertir-se aplicando inconsistentemente tal método, adotando uma teoria de forma um pouco frouxa, ou outra forma da teoria, ou a teoria do Outro. Freud quem nos diz que a lógica não faz muito sucesso junto ao inconsciente, que ele prefere os raciocícios frouxos, e por isso produz defesas como a do pobre que recebeu uma esmola e foi gastá-la com maionese de salmão: "Se não tenho dinheiro, não posso comer maionese de salmão; se o tenho, não devo comer maionese de salmão. Bem, quando vou então comer maionese de salmão?"' (Freud, 1905:67). A propósito deste e de outros chistes de deslocamento, comenta Freud:

"Não se põe em dúvida que é mais fácil e conveniente divergir de uma linha de pensamento que então se assumia do que mantê-lá, tanto quanto é mais fácil confundir coisas diferentes do que contrastá-las de fato; é especialmente conveniente admitir como válidos métodos de inferência que sấo rejeitados pela lógica e, finalmente, reunir palavras ou pensamentos sem respeitar a condição de que façam sentido" (Freud, 1905:147).

Os dados apresentados em (1), e cuja análise foi efetuada em nível suficiente apenas para explicar os elementos mínimos necessários para a argumentação que se segue, revelam, ao contrário do que se pode pensar quando apenas se ri diante de fatos como estes, interessantes problemas para a discussão do sentido, mais especificamente, da relação entre som e sentido. Sem entrar em maiores detalhes, pode-se dizer que as definições de Millôr são efetuadas segundo um princípio que poderia ser assim enunciado: do mesmo significante corresponde sempre o mesmo significado. O sentido não "desliza", mas depende desta regra, deste princípio. 
Sabe-se, no entanto, que as relações entre som e sentido não são assim tão simples, nas línguas naturais. Ao contrário, tais relações constituem um dos mistérios da linguagem, e, portanto, um dos que devem ser encarados pela linguística, talvez para serem "dissolvidos" (ver Lahud, 1977). Os diversos estruturalismos têm certamente muitas limitaçõess, mas mostraram, com bastante consistência, que a relação do significante e do significado não é automática, e sim depende de algum tipo de sistema. Como a língua enquanto tal não é provavelmente um sistema, o resultado usual é que nem sempre a mesma (porção de uma) cadeia sonora é associada ao mesmo sentido. A associação depende, por exemplo, do pertencimento da sequiência sonora a um paradigma, ou, em outros termos, a um subsistema da língua.

Mas, apesar de poder-se considerar que tal demonstração feita pelos estruturalismos é relativamente rigorosa, ela só seria válida se as línguas naturais desempenhassem apenas uma função, se servissem para produzir apenas um tipo (de efeito) de sentido por exemplo, a informação. As análises linguíisticas, entre elas as estruturalistas, privilegiam usualmente a função representativa e "pública" das línguas (vou supor que haja consenso sobre o que isto seja...) . O material lingüístico se presta, no entanto, a outras investiduras, como vimos nos exemplos acima, onde a aplicação de um critério extremamente semelhante ao utilizado na análise "séria" da estrutura da língua pode produzir efeitos de humor pela exploração simultânea do funcionamento "público" e de um outro tipo de funcionamento do material lingüístico. este outro funcionamento que parece basear-se em uma só regra: se uma cadeia tem um sentido, esta cadeia terá sempre o mesmo sentido. com esta regra que se pode dizer que "destroços" significa uma dezena de coisas, ou, por exemplo, que "escravo" significa 'um antigo prego' ou uma 'antiga flor' (ex-cravo). Mas nem este princípio pode ser posto em funcionamento de modo excessivamente frouxo. Por exemplo, ele não autoriza a interpretação de "escrita" como "uma antiga crita', porque "crita" não é uma unidade da língua, nem mesmo segundo esta "teoria".

Não é só em definições tão literais em dicionários peculiares que aquele efeito se produz. A regra funciona também para o processo inverso. Se um significado vaga por aí, sem um significante 
adequado que o veicule, o princípio age para fazer com que seja adaptado um significante disponivel e bastante semelhante (a fim de que o trabalho não seja excessivo) para que o veicule adequadamente. Seguindo este corolário da regra geral é que o mesmo Millôr propõe também um dicionovário, do qual são exemplos os seguintes itens:

(2) CALIGRAFEIA - letra ruim DESABROTOAR - desabotoar um broto CARTOMENTE - uma adivinha que nunca diz a verdade ${ }^{3}$

Não é necessário explicitar muito o visível procedimento do Outro. Apenas um comentário: observe-se que se produz uma pequena alteração na palavra, de forma a fazer com que uma de suas partes, que não é outra palavra, passe a sê-lo, na condição de que, em seguida, se aplique o método da comutação do modo aplicado no dicionário etmológico. Assim, "cartomante" torna-se "cartomente", pela troca de "a" por "e", para que a sequiência passe a ter um sentido "transparente": afinal, "mente" significa 'nunca diz a verdade' (ledo engano: poderia muito bem significar outra coisa, como mostraria um bom dicionário etimológico...).

interessante observar que também a etimologia popular um caso bem conhecido e tematizado usualmente nos manuais de estudos de linguagem, ao contrário dos exemplos em tela - atua exatamente segundo esses dois procedimentos. Neste sentido, ela é uma evidência de tentativas históricas atestadas e não jocosas de tornar claro o sentido das palavras com base na mesma regra acima enunciada, que garante a relação fixa e transparente (embora arbitrária) entre som e sentido. $\overline{\mathrm{E}}$ só assim que pediatra pode ser considerado um 'médico dos pés', e não de crianças. Pela mesma razão, vasiame (forma popular correspondente a vasilhame) é associada com "vazio" (vasiame significa um conjunto de "garrafas vazias") e não com vasilha. Nestes casos, o procedimento é idêntico ao adotado no dicionário etmológico. Exemplo de procedimento idêntico ao adotado no dicionovário, na etimologia popular, é a "mudança" que se promove para que a palavra depredar faça sentido: ao invés de ser associada a "predar", "predador", já que esta associação com palavras raras não lhe garante um sentido óbvio, a não ser para poucos falantes, é alterada e passa a ser associada a "pedra", tornando-se, assim, depedrar. 
Saussure (1916:202-3) dá exemplos ainda mais interessantes: - latim carbunculus (carvãozinho) deu em alemão Karfunkel, por associação com funkeln (cintilar); o alemão da Idade Média tomou emprestada do francês a palavra aventure, de onde derivou, regularmente, abentïre e depois Abentever, por associação com Abend (o que se conta depois do jantar). Resumindo, "a força impulsora que está por detrás da etimologia popular é o desejo de motivar na linguagem aquilo que é, ou se tornou, opaco." Como recentemente declarou um lingüista francês (Vendryes), "l'étymologie populaire est une réaction contre l'arbitraire du signe. On veut à tout prix expliquer ce dont la langue est bien incapable de fournir l'explication" (Ullmann, $1962: 206$ ) .

Apresentarei a seguir, com comentários breves, já que se trata sempre da repetição do mesmo procedimento de análise, ou seja, do mesmo princípio geral acima enunciado, mais alguns dados que o corroboram:

(3) No programa humorístico "Escolinha do Professor Raimundo" há uma personagem (Mandala) cuja característica fundamental é ver racismo em tudo. E, digamos assim, fruto exacerbado do movimento pelo uso politicamente correto da linguagem... Numa certa aula, diz que não estudou a lição porque era uma lição racista. que o professor the solicitara que estudasse o "pretérito" perfeito. $E$ pergunta por que é que o professor não the mandou estudar o "branquérito" perfeito...

Este é claramente um exemplo de funcionamento radical do princípio um som, um sentido, que garante a relação automática do significante e do significado. A porção "pret-" da palavra "pretérito" é associada com a considerada idêntica ao radical "pret-" encontrável em "preto", "pretume", etc. Seguindo o mesmo princípio, a mesma personagem, em outra aula, definiu "negação" como 'monte de crioulos'. Qual a regra seguida? A mesma: associa e identifica "neg-" de "negação" a "neg-" de "nego", "negada" etc.

Veja-se agora esta adivinha:

(4) Qual o vento que os cachorros mais temem? - Furação. 
Se o leitor deste texto não analisa "furacão" em fura e cão, não pode captar o motivo pelo qual esta resposta é engraçada. E, para captá-lo, opera segundo a regra mencionada acima (fura é sempre 'fura', cỗo é sempre 'cão') .

Veja-se, agora, como o princípio opera mesmo em relação a dados de línguas diferentes:

(5) O espanhol vai visitar o papa. Para aproximar-se dele, deve atravessar um enorme salão. Quando está chegando perto, resvala e cai. O papa o ajuda a levantar-se e o saúda: Bona sera! O espanhol responde: - Mui buena, pero mucha.

A piada só pode ser entendida pela aplicação da regra segundo a qual ao mesmo significante corresponde sempre o mesmo significado, mesmo que as sequiências pertençam a línguas diferentes. Isto é, o espanhol entende o que entende porque aplica a regra e assim interpreta a fala do papa como um comentário sobre a qualidade da cera passada no assoalho de seu salão de recepções (a palavra espanhola cera tem o mesmo sentido em português ('cera' de abelha) enquanto que a palavra sera é uma palavra italiana que significa 'tarde', e o que o papa diz significa, portanto, 'boa tarde'. Este é um exemplo de fala "pública", analisada levando-se em conta parâmetros que excluem a rebeldia e os abusos do inconsciente, explorador de significantes coincidentes...).

De funcionamento muito semelhante ao do dado apresentado em (4), é o seguinte chiste que só funciona em espanhol:

(6) Num telegrama a sua mãe, o recém-casado em lua-de-mel escreve: "Yo loco, loco, y ella loquita" ("eu louco, louco, e ela louquinha", em tradução "priblica") que deve ser lido também, para que o chiste funcione, separando a cadeia de forma alternativa $e$, no caso, perfeitamente motivada: "Yo to coloco, y ella lo quita" ("eu o coloco e ela o tira", literalmente).

O que ocorre de peculiar com este texto é que ele faz o som render duplamente: o sentido é um ou outro de acordo também com os locais de segmentação da cadeia, que podem ser mais de 
um. Feita a segmentação, qualquer que ela seja, a regra acima mencionada se aplica. Neste caso, alguém poderia argumentar que a interpretação que leva em conta o inconsciente é mais motivada que a interpretação pública. Mas, para tanto, também não poderá fugir de uma confirmação empírica...

Considerem-se agora os seguintes exemplos, ainda diferentes:

(7) ANDA MEIO ESCABREADO $=$ He walks half ex-shegoated E O MEU PADRINHO $=\mathrm{He}$ is my little priest E UM MALVERSADOR $=H e$ is a bad poet

Essas são traduções apresentadas por Millôr Fernandes em seu The caw went to the swamp - A vaca foi pro brejo, da Editora Record, livro apto a fazer rir mesmo um monolíngüe, apesar de só propor traduções de expressões portuguesas para o inglês. Essas traduções só são possíveis seguindo consistentemente três procedimentos: 1) aplicação um tanto livre do princípio de comutação às sequiências (palavras do português "público") escabreado, padrinho e malversador, de forma a segmentá-las "morfemicamente" em ex-cabr-e-ado, padr-inho e mal versador, 2) aplicação cega do princípio um som, um sentido; 3) a aplicação de uma teoria da tradução segundo a qual o sentido assim descoberto na língua de partida deve ser mantido na língua de chegada. Daí a tradução de anda por walks e de escabreado por ex-she-goated, forma cuja composição, suponho, não precisa ser descrita. Observe-se, de passagem, que a regra atua também para a eliminação da ambiguiidade, e sempre de forma a fugir do sentido mais adequado ao contexto "público", preferindo-se o outro. Por isso, a forma anda é interpretada no sentido de 'locomover-se' e não como descrevendo um estado. O tratamento dos dois outros casos fica evidente. Mas é bom mencionar, em nome da explicitude que caracteriza os linguiistas, que padr- é tomado como se significasse necessariamente 'sacerdote', e também destacar o erro ortográfico que tem que ser desprezado em mal (mau = bad) versador. Mas isso não é problema nesta "teoria". parece mais um fonema... (ver Lacan, 1966:225) .4 
Vejam-se mais exemplos:

(8) Um dia mostrei um livro a uma funcionária do xerox do meu local de trabatho e lhe disse: - Olha com que é que eu estou trabalhando agora. Ela olhou, corou e sorriu, um pouco sem jeito. Editora Biasil Blackwell, organizado por J. Culler.

A funcionária leu On puns, mas, obviamente, deteve-se em "puns", que em inglês significa 'trocadilho', mas, em português, é um nome relativamente dizível, quase livre de tabu, e significa 'traque'. Ou seja, aplicou consistentemente a regra um som, um sentido, independentemente de a palavra ser de uma ou outra língua.

Ainda mais interessante é o seguinte dado:

(9) Numa história de L. F. Veríssimo, 5 um rei coleciona aves que PIAM, e dois espertalhões fazem o possível para vender-lhe, por exemplo, a xerox emplumada, que coPIA, a "voyeur de muit", que esPIA, a piorra azul, que rodoPIA, a clínica do banhado, que teraPIA, o marrecão larápio, que surruPIA, e as cócegas selvagens, que arrePIAM...

Veríssimo revela-se, nestes dados, um fanático seguidor da mesma regra que outros seguem, e por isso, a qualquer porção "pia" que encontra atribui o sentido 'pia', mesmo que isso implique em deixar as outras porções de som sem serventia alguma (exceto, talvez, em rodopia).

Veja-se a inteligente exploração dessa regra na seguinte história, bem no espírito da personagem de um seriado de TV, um verdadeiro "bricoleur" cuja principal característica é fazer render qualquer material, transformando-o em arma ou ferramenta:

(10) - Como é que o MacGiver consegue fugir de um deserto, só com uma laranja e um canivete?

- ?

- Com o canivete, ele corta a laranja. O que é que tem na laranja? Vitamina. Joga fora a vita e fica só com a mina. Explode a mina, e provoca um terremoto. Joga fora a terra, pega a moto e vai embora.

A análise é a mesma. Fica-se com as porções das palavras que interessam ("mina" e "moto"), e atribui-se a elas um sentido segundo a regra de transparência mencionada. 
E corrente a idéia (em Análise do Discurso, em psicanálise, etc) de que estes exemplos servem para sustentar, embora não só eles, pontos de vista segundo os quais os sentidos não são univocos, não são transparentes, e não podem representar as intenções dos falantes, pois que decorrem não de uma relação transparente entre som e sentido, mas, ao contrário, de um desequilíbrio entre os dois componentes do signo, desequilíbrio esse que favorece o significante, tornada uma espécie de máquina imprevisível de produção de sentidos (segundo hipótese da Análise do Discurso, a imprevisibilidade pode ser controlada através do apelo às condições de produção) . Também não podem representar as intenções dos falantes, pois decorrem de uma história complexa de discursos. Sabe-se também que esta concepção pretende-se tributária de Saussure, que teria, por exemplo, servido como fornecedor de um ponto de vista sobre a linguagem, utilizado, por exemplo, por Lacan para reler Freud. E por isso que a palavra "significante" (e mesmo a palavra "estrutura", um pouco estranhamente, como estou pretendendo mostrar) faz parte do arcabouço teórico de Lacan e de outros analistas da linguagem que aceitam de alguma maneira esta relação desigual entre significante e significado.

Ora, parece não ser exatamente de Saussure que estas conclusōes podem ser tiradas. Voltemos ao estruturalismo, fazendo uma rápida excursão pela história, seguindo Ducrot (1968). Sabe-se que a relação entre os componentes do signo lingüístico nem sempre foi considerada arbitrária. conhecida a velha hipótese segundo a qual as palavras originárias tenham tido uma relação direta quer com as coisas - "...a língua original poderia talvez pintar seu objeto por meio de sua própria substância fônica" (Ducrot, 1968:27) quer com o pensamento - idéia expressa na hipótese de que a língua seja o espelho do pensamento, chegando a imitar-lhe a ordem, as partes, etc.

A descoberta do estruturalismo consistiu exatamente em dizer que as partes da língua subsistem independentemente das coisas e do pensamento, que elas só se relacionam consigo mesmas. Este tipo de análise começa na verdade um pouco antes do estruturalismo. Segmenta-se navegação, por exemplo, e nela encontra-se um verbo associado a um sufixo. Segundo Ducort, "a originalidade (...) não é operar tal tipo de segmentação, mas recusar-se a operar outras, por não serem regulares numa língua. Interditando-se 
análises fantasiosas, valorizam-se as novas. Passa-se a zombar de etimologias "motivadas", que viam em lepus (lebre) um composto de levis (ligeiro) e pes (pés)" (Observe-se a semelhança com exemplos como janota, consumo, etc., do dicionário etmológico de Millôr.). Se se perguntar agora quais razões podem autorizar a análise de navegação e não de lepus, quando ambas são semanticamente motivadas (e a segunda, inclusive, bem mais que a primeira), a resposta é que a adição de - ção a um radical verbal constitui em português um procedimento regular, ao passo que não se pode encontrar em latim esquema geral de composição de que le-pus fosse uma aplicação particular. (...) o arranjo interno da palavra é justificado não do ponto de vista da realidade, mas com relação a um hábito linguiístico constante" (ver Ducrot, 1968:31-2).

A versão mais conhecida do conceito de signo na lingüística saussuriana é a que o define pela associação arbitrária entre significante e significado. Mas esta não é a escolha definitiva de Saussure: a marca distintiva de sua concepção é a teoria do valor, segundo a qual os signos (sem excluir tal relação arbitrária) se definem opositivamente, isto é, cada um é o que é porque não é nenhum outro. Esta a característica que faz da língua um sistema, uma estrutura. A doutrina de Saussure fica mais clara se recordamos que ele mostra como a palavra desfazer se encontra na intersecção de duas séries: a dos compostos de fazer (refazer, contrafazer...) e a dos compostos de des- (descolar, descoser...). Desfazer deixaria de ser composto se des- ou fazer desaparecessem (Saussure, 1916:150) ou mudassem de sentido. Por isso, des- não é um prefixo em desmanchar, por exemplo, embora no início desta palavra se encontre, num certo sentido, um elemento idêntico à sequiência des- que se encontra em desfazer. A razão é que, sem o falso prefixo des-, manchar não mantém o mesmo sentido que tem em desmanchar (na verdade não tem nenhum...), e sem isso, do ponto de vista estrutural, não existe a palavra composta. Saussure discutiria com Veríssimo, por exemplo, e tentaria convencê-lo de que não adianta encontrar muitas ocorrências de "pia", já que o que sobra não é outro signo. Refiro-me ao Saussure do Curso, claro, não ao dos anagramas...

O que fazem os exemplos (1)-(10) ? Produzem um certo efeito explorando uma noção simplificada de signo, baseada apenas na relação significante-significado e fazem a língua funcionar num 
domínio específico como se uma relação local e coincidente se mantivesse em todos os domínios. Isto é, como se a língua fosse uma nomenclatura (concepção que Saussure combate ${ }^{6}$ ) e não um sistema ou uma estrutura.

Como disse acima, os casos aqui apresentados são exemplos (não os únicos, pelo contrário) da linguagem do Outro (ver Authier- Révuz, 1982, passim). Dados como estes são constantemente invocados como evidências contra a centralidade da razão e a unicidade do sujeito. Poder-se-ia dizer que a tese é fraca porque estes dados são marginais, e sobre eles não se pode sustentar uma teoria. Mas, se é verdade que não é assim que a língua funciona publicamente (quando se lê ou ouve dizer que houve uma disputa entre partidos, não entendemos que houve uma "afirma prostituta penetre despedaçados"), e, portanto, esses dados não resistem a testes de tipo científico como os adotados pelas teorias lingüísticas, não se pode desconhecer que o tipo de funcionamento aqui exemplificado ocorre com uma frequiência fora do comum, em variadas funções estéticas. Por um lado, isso parece levar água ao moinho de Lacan, que afirma a prevalência do significante sobre o significado. Mas, por outro, como vimos, as análises de tais materiais só se sustentam pela hipótese da união indissolúvel do significante e do significado.

Se a linguagem do Outro estiver exemplificada por esses dados, teremos que discutir seriamente a possibilidade de o inconsciente não ser uma estrutura (se for estruturado do mesmo modo que essa sua linguagem), mas uma nomenclatura ("... lista de termos que correspondem a outras tantas coisas", Saussure, 1916:79) . Fica-se, assim, com a sensação de que Lacan fez um uso peculiar não só da noção de significante, mas também da noção de estrutura. Além do mais, teríamos que aceitar que o inconsciente fala como se aceitasse que o sentido é literal e fixo; ao invés de deslizar, seus significados seguem os significantes onde quer que eles estejam.

Se estes exemplos forem evidências de que as línguas não são estruturas, no sentido técnico, tese defendida nos melhores meios (ver, por exemplo, Granger, 1960 e Franchi, 1977) eles são benvindos. O que parece inadequado é utilizá-los exatamente para declarar-se estruturalista e devedor de Saussure. 
Por isso, para encerrar, nada melhor do que as palavras de Freud (1905:142): "as crianças, ainda acostumadas a tratar as palavras como coisas, tendem a esperar que palavras idênticas ou semelhantes tenham, subjacente, o mesmo sentido".

\section{NOTAS}

1

As "traduções" que aparecem entre parênteses são minhas.

2

Um dos defeitos da psicanálise, segunndo Mitsout Ronat, citada em Gadet \& Pêcheux (1981:217) é ter uma concepção muito simples da língua. Segundo a autora, parece não considerar ambigüidades sintáticas e, muito menos, lapsos sintáticos.

3

Os dados de (1) e (2) foram extraídos de Paulillo, M. C. R. de A. (1980). Millór Fermandes. São Paulo, Abril Cultural. (Coleção Literatura Comentada).

\section{REFERENCIAS BIBLIOGRAFICAS}

AUTHIER-REVUZ, J. Hétérogénéité montrée et hétérogéneité constitutive: éléments pour une approche de lautre dans le discours. $D R L A V$. v. 26, p. 91-151, 1982 .

DUCROT, O. Estruturalismo e lingiïstica. São Paulo: Cultrix, 1968.

FRANCHI, C. Linguagem - atividade constitutiva. In: Almanaque. Săo Paulo: Brasiliense, 1977. v. 5, p. 9-27.

FREUD, S. Os chistes e sua relação com o inconsciente. Rio de Janeiro: Imago Editora, 1905.

GADET, F. \& PECHEUX, M. La langue introuvable. Paris: Maspero, 1979.

GRANGER, G.-G. Língua e sistemas formais. In: SUMPF et al. Filosofia da linguagem. Coimbra: Livraria Almedina, 1960. p. 139-171.

LACAN, J. A instância da letra no inconsciente ou a razão desde Freud. In: Escritos. São Paulo: Editora Perspectiva, 1966. p. 223-259.

LAHUD, M. Alguns mistérios da lingüística. In: Almanaque. São Paulo: Brasillense, 1977. v. 5, p. 28-37.

SAUSSURE, F. de. Curso de lingüistica geral. São Paulo: Cultrix, 1916.

STAROBINSKY, J. As palavras sob as palavras: os anagramas de Ferdinand de Saussure. São Paulo: Perspectiva, 1971.

ULLMANN, S. Semantica: uma introdução à ciêncla do significado. Lisboa: Fundação Calouste Gulbenkian, 1962. 